\title{
A cultura é acessível a todos? \\ A função do intelectual orgânico como forma de debelar a imposição da hegemonia da classe dominante.
}

\author{
¿La cultura es accesible a todos? \\ La función do intelectual orgánico como una manera de superar la \\ imposición de la dominación de clase dominante. \\ Is the culture accessible for everyone? \\ The function of the organic intellectual as a way to overcome the \\ imposition of the dominant class hegemony.
}

\section{Lilian Coelho Tavares da Cunha Mello ${ }^{1}$ Rafaela de Souza Ribeiro ${ }^{2}$}

\begin{abstract}
Resumo
A cultura consiste em uma complexa palavra presente em distintos espaços da sociedade contemporânea. Apreender a cultura como instrumento potencializador de consciência crítica nos permite pensar a função do intelectual orgânico frente a hegemonia da classe dominante. A sociedade contemporânea, recheada por processos hegemônicos que inibem a potencialidade revolucionária da classe trabalhadora, é campo que, a partir do referencial teórico gramsciano e marxista, tornar possível a construção desse trabalho. O desafio está na construção de estratégias para o alcance da consciência de uma classe "para si" - nas palavras de Gramsci - onde por intermédio da resistência e da ação coletiva uma nova sociedade é possível.
\end{abstract}

Palavras chaves: Identidade, Cultura, Intelectual orgânico, Hegemonia

Resumen

La cultura consiste en una palabra compleja presente en diferentes ámbitos de la sociedad contemporánea. Aprehender la cultura como herramienta de conciencia crítica agravante nos permite pensar sobre el papel de la parte delantera intelectual orgánico de la hegemonía de la clase dominante. Los procesos de la sociedad contemporánea llena hegemónico que inhiben el potencial revolucionario de la clase obrera de campo, es decir, desde el teórico marxista y Gramsci, haciendo posible la construcción de esta obra. El reto es construir estrategias

para lograr la conciencia de una clase "para sí mismo" - en palabras de Gramsci - que a través de la fuerza y la acción colectiva de una nueva sociedad es posible.

Palabras clave: identidad, cultura, intelectual orgánico, Hegemonía

\footnotetext{
${ }^{1}$ Graduanda em Serviço Social; Universidade Federal do Estado do Rio de Janeiro - UNIRIO; Rio de Janeiro, RJ, Brasil; lilianctcmello@gmail.com.

${ }^{2}$ Mestre em Serviço Social; Universidade Federal do Estado do Rio de Janeiro UNIRIO; Rio de Janeiro, RJ, Brasil; ribeiro.rafaela@gmail.com. Trabalho apresentado no I Seminário Latino-Americano de Estudos em Cultura - SEMLACult, Foz do Iguaçu/PR, Brasil, 2017.
} 


\begin{abstract}
Culture consists of a complex word present in distinct spaces of contemporary society. Seizing culture as a powering instrument of a critical awareness allows us to think about the function of the organic intellectual face of the dominant class hegemony. The contemporary society, filled with hegemonic processes that inhibit the revolutionary potentiality of the working class is field, which, according to Gramscian and Marxist theoretical referential, makes this work possible. The challenge is in the strategies construction to reach the awareness of a class "for itself" - in Gramsci words - which through resistance and collective action a new society is possible.
\end{abstract}

Key words: Identity, Culture, Organic Intellectual, Hegemony

\title{
1. Introdução
}

O presente artigo vislumbra construir um olhar sobre a noção de cultura na modernidade, das contraposições que o termo carrega no desenvolvimento da historicidade da sociedade, seus principais usos dentro da teoria social crítica. O caminho a ser percorrido será fazer uma breve revisão bibliográfica acerca do conceito de cultura e sua contribuição para pensar o papel do intelectual orgânico, categoria marxista desenvolvida por Antônio Gramsci. Pretende a partir das idéias fundamentadas principalmente em autores marxistas a visualização do novo intelectual para uma nova sociedade, traçando reflexões sobre esta categoria gramsciana, para o novo formador de consciência. Introduzir reflexão a crítica de importantes autores como Antônio Gramsci (1982), Raymond Willians (1983), Marilena Chauí (2011), Giovanni Semeraro (2006).

\section{Cultura na modernidade e as contraposições do termo no desenvolvimento histórico}

"Cultura" é considerada uma das duas ou três palavras mais complexas de nossa língua (...)", Raymond Willians (1983), em seu livro "Palavras-Chave [um vocabulário de cultura e sociedade]" não carrega o objetivo somente de distinguir o uso dos termos, das palavras-chave do sistema de referência da sociedade moderna, como: a arte, a cultura, estética, democracia, classe, verdade, indústria, ideologia etc. Seu intuito é associá-las às suas origens e efeitos.

Raymond Williams (1983) tem como objetivo em seus escritos fazer reflexões para contribuir com a história, ajudar a compor a história da sociedade moderna e, preocupa-se em mostrar as contraposições, e contradições que os termos carregam, verdadeiros conflitos sociais, e como predominância de um sentido sobre o outro e resultado da prevalência de uma ideologia em relação à outra, onde expressa a consciência moderna de visão de mundo característica da sociedade em que o capitalismo está definitivamente implantado.

Ao realizar ampla revisão dos fatos relativos à história cultural evidencia o modo como as palavras foram historicamente construídas, percebendo a complexidade do conceito 
de cultura no seio das relações sociais e com isso observa o sistema de significados do mundo contemporâneo e, quebra com a visão dominante de que os significados dos termos são imutáveis e a histórico.

\begin{abstract}
A cultura é de todos: este o fato primordial. Toda sociedade humana tem sua própria forma, seus próprios propósitos, seus próprios significados. Toda sociedade humana expressa tudo isso nas instituições, nas artes e no conhecimento. A formação de uma sociedade é a descoberta de significados e direções comuns, seu desenvolvimento se dá no debate ativo e no seu aperfeiçoamento, sob a pressão da experiência, do contato e das invenções, inscrevendo-se na própria terra. A sociedade em desenvolvimento é um dado, e, no entanto, ela se constrói e reconstrói em cada modo individual de pensar.(WILLIAMS, R. 1958)
\end{abstract}

Raymond Willians revela que não poderia se limitar ao conceito de cultura, já que na estrutura de seus significados, no desenvolvimento histórico da palavra observa na verdade "um movimento amplo e geral de idéias e sentimentos" (WILLIAMS, 1969, p.19).

Michael Löwy (2016, p.42-44), em seu artigo evidencia as convicções do intelectual que renovou o pensamento marxista sobre cultura e relata que Raymond Willians define "seu método como um materialismo cultural, isto é, uma aproximação dos fatos culturais não como figuras do espírito ou como simples objetos, mas como um conjunto de práticas e de instituições em relação estreita com as classes sociais". Willians propõe abordar as relações entre produções culturais e processos socioeconômicos por meio da categoria lukacsiana de "totalidade" ressaltando, contudo, a partir da categoria gramsciana de "hegemonia", o papel das ideologias na hegemonia das classes dominantes.

"Massificar é o contrário de democratizar a cultura. É a negação da democratização da cultura.” (CHAUÍ, 2011). Marilena Chauí (2011) relata que a origem do termo cultura significa 'cultivo', cultura era concebida como uma ação que conduz à plena realização das potencialidades de alguma coisa ou de alguém. No século XVIII a palavra cultura ressurge como sinônimo de 'civilização', se torna o padrão e o critério que mede o grau de civilização de uma sociedade" e sendo encarada como um conjunto de práticas (artes, ciências, técnicas, filosofia, os ofícios) hierarquizadas segundo um critério de evolução, torna-se sinônimo de 'progresso'.

Histórico do artigo:

Submetido em: 04/05/2017 - Aceito em: 16/05/2017 O conceito de cultura reaparece no século XIX, associado a ideia de progresso, onde se estabeleceu um padrão para medir a evolução de uma cultura e esse padrão foi evidentemente o da Europa capitalista. As 
sociedades passaram a ser avaliadas segundo a presença ou a ausência de alguns elementos e a ausência desses elementos foi considerada como sinal de falta de cultura, ou de uma cultura pouco evoluída. Todas as sociedades que desenvolvessem formas de troca, comunicação e poder diferentes do mercado, da escrita e do Estado europeu foram definidas como culturas "primitivas". Em outras palavras, foi introduzido um conceito de valor para distinguir as formas culturais. (CHAUÍ, 2011)

Marilena Chauí (2011) ressalta que essa noção do 'primitivo' e 'não primitivo', torna os critérios como definidor da essência da cultura, e isso implica num juízo de valor.

“A cultura européia capitalista não apenas se coloca como o fim necessário do desenvolvimento de toda cultura ou de toda civilização, sobretudo se oferece como modelo necessário do desenvolvimento histórico, legitimando e justificando a colonização e o imperialismo", segundo (Chauí, 2011)No século XIX a noção de cultura é encarada como a ruptura à natureza, inaugurando o mundo humano propriamente dito. A dimensão humana da cultura é um movimento de transcendência, que põe a existência como o poder para ultrapassar uma situação dada graças a uma ação dirigida àquilo que está ausente.

\begin{abstract}
A sociedade de classes institui a divisão cultural e pode-se falar em cultura dominada e cultura dominante, cultura opressora e cultura oprimida e cultura de elite e cultura popular. Seja qual for o termo empregado, o que se evidencia é um corte no interior da cultura entre aquilo que se convencionou chamar de cultura formal, ou seja, a cultura letrada, e a cultura popular que corre espontaneamente nos veios da sociedade. (CHAUÍ, 2011)
\end{abstract}

A partir de meados do século XX, a concepção ampliada da cultura será incorporada desfazendo a ideologia etnocêntrica e imperialista da cultura, inaugurando a antropologia social e política, nas quais cada cultura exprime, de forma historicamente e materialmente determinada. A ordem humana simboliza uma individualidade própria ou uma estrutura própria. $\mathrm{O}$ termo cultura passa a ter uma abrangência que não possuía antes, passa a ser compreendida como o campo no qual os indivíduos elaboram símbolos e signos, instituem as práticas e os valores e definem para si próprios o possível e o impossível, definem também os valores como o verdadeiro e o falso, o belo e o feio, o justo e o injusto, instauram a idéia de lei, e, portanto, do permitido e do proibido, determinam o sentido da vida e da morte. (CHAUÍ, 2011)

\title{
3. Considerações a partir das reflexões Gramsciana da categoria "Intelectual orgânico"
}

A idéia de cultura e organização da cultura pode ser visualizada pelas categorias que Gramsci pensou para entender as relações sociais da sociedade na época que ele vivia na 
Itália, "intelectual" e "hegemonia", categorias que vão apresentar relação e correlação de forças existentes nas relações sociais no sistema vigente, o capitalismo.

Evidencia-se uma relação antagônica de classes, com domínio de uma classe sobre a outra onde a classe dominante impõe seus processos culturais e econômicos com único objetivo de acúmulo de riquezas, o de gerar mais valor, anulando a identidade dos sujeitos nas relações sociais. Em suas reflexões criticas percebeu como funciona a pirâmide social e quem direciona a cultura como modo de vida, observou em estudo aprofundado, quem executa esse direcionamento no modo de ser da vida dos sujeitos.

“Todos os homens são intelectuais, poder-se-ia dizer então; mas nem todos os homens desempenham na sociedade a função de intelectuais.” (GRAMSCI, 1982, pág.7)

Gramsci cristaliza em seus estudos a teoria da filosofia da práxis revelando que todo ser social é um intelectual, dotado de inteligência e todo sujeito pode ser um intelectual e, ressalta que quem detém a hegemonia detém o poder. Se esse intelectual é um intelectual ligado às massas, um dirigente que move as consciências e orgânico ao seu projeto societário, ele pode estar dentro de qualquer classe social.

Deve-se notar que a elaboração das camadas intelectuais na realidade concreta não ocorre num terreno democrático abstrato, mas de acordo com processos históricos tradicionais muito concretos. Formaram-se camadas que, tradicionalmente, "produzem" intelectuais; trata-se das mesmas camadas que, freqüentemente, especializaram-se na "poupança", isto é, a pequena e média burguesia fundiária e alguns estratos da pequena e média burguesia das cidades. A diversa distribuição dos diversos tipos de escola (clássicas e profissionais) no território "econômico" e as diversas aspirações das várias categorias destas camadas determinam, ou dão forma, à produção dos diversos ramos de especialização intelectual. Assim, na Itália, a burguesia rural produz notadamente funcionários estatais e profissionais liberais, ao passo que a burguesia urbana produz técnicos para a indústria: por isso, a Itália setentrional produz notadamente técnicos e a Itália meridional notadamente funcionários e profissionais. (GRAMSCI, 1982, p.10)

Segundo Gramsci (1982), “A relação entre os intelectuais e o mundo da produção não é imediata, como é o caso nos grupos sociais fundamentais, mas é "mediatizada", em diversos graus, por todo o contexto social, pelo conjunto das superestruturas, do qual os intelectuais são precisamente os "funcionários". 
Segundo Semeraro (2006) quando Gramsci em seus estudos pensou o "Intelectual" do seu tempo na Itália, ele fez uma comparação, observando a diferença entre a Itália setentrional e meridional, compara a Itália mais agrária e a mais urbana e desenvolvida, no cenário histórico que vivenciava, início do capitalismo, na época da industrialização na Itália, na migração do êxodo rural, quando ele refletia sobre isso observa que os intelectuais tinham papel principal dentro daquela sociedade, que existiam diferentes tipos de intelectuais, os considerados mais tradicionais, que tinham origens nas castas: clero, representantes da igreja, da cúpula do Estado. Os que detinham de fato um poder tradicionalmente de herança, inclusive de herança cultural (clero da corrente do catolicismo), e já era sabido que estes intelectuais exerciam papel fundamental nessas sociedades, porém com a industrialização e com a nova sociedade emergindo, novas figuras foram também surgindo, observando toda essa dinâmica da vida moderna nas relações sociais, aprofunda seus estudos na categoria "intelectual orgânico", os novos intelectuais.

Gramsci (1982) observa, que esses intelectuais estão orgânico às classes subalternizadas, não que sejam somente da classe subalternizada, classe trabalhadora e diferentes setores da classe trabalhadora, o intelectual orgânico pode estar em qualquer classe e seguimento de classe, exercendo o papel orgânico à proposta de intervenção de sociedade, àquele projeto societário determinado, e deve ter organicidade com um projeto societário vinculado organicamente a esta proposta de sociedade. Gramsci (1982) percebe o surgimento de novos intelectuais atuando como agentes na sociedade.

Para visualizar a figura do intelectual na contemporaneidade de acordo com o marxismo, que está vinculado ao pensamento crítico dialético no interior das ciências sociais é muito importante associar à figura do intelectual ao dirigente de uma sociedade, ter claro quem exerce o papel do dirigente de uma classe ou projeto de uma classe, assim como a quem detém o poder, e quem são os verdadeiros dirigentes de uma sociedade.

De acordo com Semeraro (2006), Gramsci foi o pensador que se aprofundou na categoria "intelectual" e explorou a figura do intelectual por perceber essa atuação desses agentes na sociedade, e viabiliza o conceito de "intelectual" para as grandes massas, quebra com visão

dominante da figura do intelectual vinculada apenas a uma alta cultura, a uma proposta elitista de sociedade, quando pensa essa nova forma de intelectual, divulga e populariza a função desse "intelectual orgânico", esse "novo intelectual" se cristaliza na sua proposta metodológica, a teoria da filosofia da práxis. 
Segundo Semeraro (2006), Karl Marx já vinha pensando a figura desse novo intelectual quando sinaliza que o novo homem precisa surgir e estar vinculado às novas requisições que a sociedade industrial vinha trazendo. Karl Marx reconhece que a proposta desse novo homem tem que estar vinculado à classe trabalhadora, as classes subalternizadas e que somente com esse vínculo estreito a essas classes talvez seja possível à mudança de ordem de projeto societário.

O conceito gramsciano "intelectual orgânico", se populariza, e vai se espraiar para o conceito geral de ser social, sobre que o homem transforma a matéria da natureza por meio do trabalho para refinar suas necessidades. Karl Marx (1983) relatava em seus escritos sobre a "ontologia do ser social". Gramsci vai além e acrescenta, sobretudo na teoria do valor do trabalho, a nova forma, a nova possibilidade do ser social ser dotado de inteligência e de que todo sujeito pode ser um intelectual e, isso denota um avanço na teoria dele de "intelectual orgânico" em que a qualidade desse intelecto não vai se diferenciar, o que vai se diferenciar é a quantidade desse intelecto, não tendo a ver com a natureza do saber, já que se pode deter saber em qualquer área de trabalho, mas com a possibilidade que o sujeito teve de desenvolver esse saber.

Devido a isso que Gramsci (1982) considera que todo ser social é um intelectual, mas a cultura é que vai importar para o desenvolvimento do intelecto, é a cultura que vai definir qual o tipo de intelectual que se tornou ou o que não se tornou.

Marx (1983) ressaltava que a qualidade do acesso que vai formar o tipo de intelectual, sobretudo as relações sociais e culturais que serão definidoras dessa quantidade de saber que um intelectual possui.

As considerações marxiana sobre o papel do intelectual para a conquista de uma sociedade verdadeiramente democrática que exige a necessidade emergencial de um projeto alternativo oriunda no proletariado, para a conquista da sua hegemonia de classe, com apoio dos intelectuais "onde a filosofia encontra no proletariado as suas armas materiais, assim como o proletariado encontra na filosofia as suas armas espirituais" (Marx, 1983, p.173, apud. Semeraro, p.375). Relação dialética para Marx com relação à filosofia e as coisas do espírito e as relações sociais materiais, nas quais o proletariado e a classe trabalhadora estão vinculados. 
Para Gramsci (1982) tanto os intelectuais voltados a determinado saber específico, quanto os intelectuais que estão no interior da classe trabalhadora, contraem uma relação de simbiose e

complementar onde o intelectual vai precisar estar vinculado a um saber específico ou a uma burocracia específica a um tipo de filosofia, vai precisar ter contato com essa classe trabalhadora para se imbuir espiritualmente das vivências dessa classe trabalhadora e das mazelas dela, e dos males dessa classe burguesa de sociedade. Essa relação de filosofia, ciência e a materialidade das relações sociais, não podem estar uma descolada da outra, assim como na materialidade das relações sociais, essas mazelas vão se apresentar diretamente, sendo necessário poder extrapolar o cotidiano.

Gramsci (1982) ressalta sobre o 'senso comum x bom senso' do cotidiano e, de chegar a um pensamento crítico a respeito desse próprio cotidiano na qual todos estamos interligados, então a filosofia também importa para a vivência dessas relações sociais, não sendo uma relação excludente. Gramsci ressalta na teoria da filosofia da práxis, que só filosofia, só as relações materiais ou as coisas do espírito, e vice versa, um excluindo o outro, onde tipos diferentes de intelectuais não podem conviver, e que Gramsci chama isso de "erro metodológico", quando tipos diferentes de intelectuais não podem conviver, tendo que prevalecer apenas um tipo de intelectual.

$\mathrm{Na}$ verdade o intelectual que se considera mais desenvolvido, na figura do novo intelectual, a serviço da mudança da ordem societária, que não esteja mais vinculado às burocracias da sociedade tecnológica pós-industrial. Onde as relações se apresentam mais efêmeras por conta dessas novas relações sociais que se impõem e que bombardeiam as relações sociais.

Ocorre que quando isso acontece, um novo intelectual se impõe nessas relações de poder vinculado à classe burguesa, onde o que importa de fato são as aparências das coisas, o belo, a estética, o bom que a mídia vai impor. Chauí (2006, p.8-9) afirma a desinformação como falsa consciência, que usa da ilusão de que a propaganda é informação, usando de exemplos pessoais para ditar normas sociais, desconsiderando as construções sociais.

A cultura é de todos! O que fazer para mudança de ordem societária?

A emergência de um projeto alternativo vinculado à classe trabalhadora que precisa estar trabalhando para mudança da ordem societária, se imbuir de espírito critico, para que o novo intelectual não seja levado por essa visão imposta pela sociedade, que nos empurra a qualquer custo, acriticamente, e que a hegemonia da classe dominante e seus aparelhos 
ideológicos seguem impondo a sua cultura de massa na sociedade civil, onde o que importa é o aqui e agora, "Just time" do modo de trabalho das relações sociais de produção e que sob a égide das relações econômicas de produção, que vem requerendo a imposição dos conglomerados globais, que tocam a economia global não mais localmente ou multinacionalmente.

A visão de Gramsci em contraposição a algumas teorias que já falavam da possibilidade da chegada de uma nova cultura, quando se pensa a figura de "intelectual orgânico" pensando em Gramsci, existe na pós-modernidade alguns autores pensando nessa mudança de cultura, numa retomada e virada na proposta cultural, com a idéia de fim da meta narrativa, fim da história. Esse novo homem está muito mais vinculado ao papel gerencial de intelectual gerencial das grandes propostas de difusão de poder do que a própria classe trabalhadora, o que se tem de interessante nessa nova proposta é exatamente a sociedade da informática, a sociedade gerencial, propostas antigas que estão vinculadas a filosofia e ciência foram descartadas. Por isso que tem-se a idéia de fim das metas narrativas nessa vertente da pósmodernidade, penso nisso e logo vem a mente a idéia de fim da meta narrativa, fim da sociologia, fim da história, fim da ciência, e tem a ver com essas propostas que foram mantidas obsoletas para resolver os problemas da humanidade. Segundo essa vertente, nem a política e nem a filosofia podem solucionar os problemas do mundo, e que as novas tecnologias, novas formas de gerenciar a sociedade é que vão solucionar, otimizando, tempo, espaço, e trabalho que darão conta das questões dessa sociedade.

A interconexão do mundo do trabalho com o universo da ciência, com humanidades e a visão política de conjunto formam o novo princípio educativo e a base formativa do “intelectual orgânico".

São orgânicos os intelectuais que, além de especialistas na sua profissão, que os vincula profundamente ao modo de produção do seu tempo, elaboram uma concepção ética-política que os habilita a exercer funções culturais, educativas e organizativas para assegurar a hegemonia social e o domínio estatal da classe que representam. (GRAMSCI, 1975, p.1518, apud. SEMERARO, 2006, p.378)

De acordo com (GRAMSCI, 1975), a função do novo intelectual orgânico à dinâmica da sociedade, pode ter origem na classe trabalhadora, ou estar no interior de uma classe dirigente dessa sociedade vigente, independente da classe que ele está orgânico, mas estar orgânico à conquista da hegemonia da sua classe, não pode mais consistir "na eloqüência" e 
nos ímpetos da "emoção", mas na interpenetração entre conhecimento científico, filosofia e ação política.

Refletir sobre os processos e práticas culturais neste cenário histórico na atualidade em que a informação ganhou alcance e formatos inéditos para pensar um novo intelectual orgânico nos moldes de Gramsci, neste sistema caótico de modo de produção de trabalho é realmente um enorme desafio.

Semeraro (2006) relata que Marx já vinha pensando na possibilidade da classe trabalhadora retomar o poder por meio da sua própria cultura e da vivencia das relações sociais dentro da classe e que assim pode ser a possível a mudança de ordem societária levando a cabo seu saber, viabilizar esse saber e em que instâncias os sujeitos da classe trabalhadora podem flexibilizar e aumentar a sua visão crítica da realidade em que eles mesmos estão vinculados. Pensar nessa figura de intelectual nesta sociedade com as interferências da despolitização, é desafiador, mas Antônio Gramsci a serviço da classe trabalhadora defende uma ampla e rigorosa formação do intelectual orgânico, uma vez que a filosofia da práxis, além de representar "o coroamento de todo o movimento de reforma moral e intelectual", deve ser a reinvenção de um novo intelectual que sabe sintetizar o melhor da filosofia, da política, da economia, da ciência, e da arte. (GRAMSCI, 1996, Carta de 01/08/1932, apud. SEMERARO, 2011, p.384).

\section{Referências}

CEVASCO, M. Elisa. Dez lições sobre estudos culturais. $3^{\text {a }}$ ED. SP: Boitempo Ed, 2012.

CHAUÍ, Marilena. Cidadania cultural: o direito à cultura. São Paulo: Editora Fundação Perseu Abramo, 2006 (Apresentação + Cap. 1: Sobre o nacional e o popular na Cultura p.15$64)$.

CHAUÍ, M. Cultura e democracia: o discurso competente e outras falas. Cap.3 e 4 (Cultura do povo e autoritarismo das elites / Notas sobre cultura popular, p.49-79). 13 ${ }^{\mathrm{a}}$ ed., SP: Cortez, 2011.

CHAUÍ, M. Simulacro e poder: uma análise da mídia. São Paulo: Editora Fundação Perseu Abramo, 2006, (P. 5 a 30).

COUTINHO, C.N. Gramsci, o marxismo e as Ciências Sociais. In: Marxismo e Política. A dualidade de Poderes e outros ensaios. $2^{a}$. edição. São Paulo: Cortez Editora, 1996.pp. 91-120. COUTINHO, Carlos Nelson. Cultura e Sociedade no Brasil: Ensaios sobre ideias e formas. São Paulo: Expressão popular, 2011. $4^{\mathrm{a}}$ Ed. (Dois momentos Brasileiros da Escola de Frankfurt" p.73-88). 
EAGLETON, Terry. A ideia de cultura; tradução Sandra Castello Branco; revisão técnica Cezar Mortari. $2^{a}$ ed. São Paulo: Editora Unesp. 2011, (p.9-50).

GRAMSCI, A. Cadernos do Cárcere. Americanismo e Fordismo. Cardeno 22, (Vol.3). Rio de Janeiro: Editora Civilização Brasileira, 2000.

GRAMSCI, A. Os intelectuais e a organização da cultura. (A formação dos intelectuais p.3-23/ A organização da escola e da cultura p. 117-127). Coleção: PERSPECTIVAS DO HOMEM, vol.48. Série Filosofia. Direção de Moacyr Felix. Tradução: Carlos Nelson Coutinho. 4ªed., Rio de Janeiro: Editora Civilização Brasileira, 1982.

LÖWY, Michael. DOSSIÊ RAYMOND WILLIAMS: Materialismo Cultural e Romantismo Anticapitalista. Artigo Revista CULT, no 217, (p. 42 - 44). Ano 19, outubro 2016. Tradução: Mario Sagayama. In: www.revistacult.com.br

HALL, Stuart. A identidade cultural na pós-modernidade. $6^{\mathrm{a}}$. edição. Rio de Janeiro: DP \&amp; A Editora, 2001.

ORTIZ, Renato. Mundialização e Cultura. (Cap.V, p. 127-182). 1ª ed. São Paulo: Editora Brasiliense, 1994.

ORTIZ, Renato. A moderna Tradição Brasileira-Cultura Brasileira e Indústria cultural, Cap. I e II (P.13-76) Cap.. IV (P.113-148)

SEMERARO, G. Intelectuais “orgânicos” em tempos de pós-modernidade. Cad. Cedes, Campinas, vol.26, n. 70, p.373-391, set./dez. 2006 In:http://www.scielo.br/pdf/ccedes/v26n70/a06v2670.pdf

SEMERARO, Giovanni. Cultura e Educação para a Democracia. Gramsci e a sociedade civil. 2a . Ed. Petrópolis: Editora Vozes, 1999.pp. 69-99.

WILLIAMS, Raymond. Palavras-chave [um vocabulário de cultura e sociedade]. Ed. Boitempo, 1983, pág.117-124 (verbete cultura)

WILLIAMS, Raymond. Cultura e Sociedade. São Paulo: Editora Nacional, 1969.

WILLIAMS, Raymond. A Cultura é de Todos (Culture is Ordinary), 1958. Trad. Maria Elisa Cevasco. Departamento de Letras. USP 